\title{
Özel Gereksinimli Bireylere Serbest Zaman Becerilerinin Öğretimine Yönelik Yapılan Araştırmaların İncelenmesi
}

\author{
Review of Research on The Teaching of Leisure Time Skills to \\ Individuals with Special Needs \\ Evgin ÇAY*
}

- Geliş Tarihi: $18.11 .2018 \bullet$ Kabul Tarihi: $18.02 .2019 \bullet$ Yayın Tarihi: 28.06 .2019

\section{$\ddot{O} \mathbf{z}$}

Serbest zaman, bireyin görev ve sorumluluklarını yerine getirdikten sonra kişisel gelişimi destekleyen, bireyi mutlu eden ve zamanını verimli geçirmesine yardım eden zaman dilimi olarak tanımlanmaktadır. Özel gereksinimli bireylerin serbest zamanlarını kaliteli ve verimli geçirmeleri önemli olduğu için alan yazında serbest zaman becerilerinin öğretimine yönelik pek çok araştırma yapılmıştır. Bu araştırmada; 2005-2018 y1lları arasında hakemli dergilerde yayımlanmış, özel gereksinimli bireylere serbest zaman becerilerinin öğretimine yönelik yurt içi ve yurt dışında yapılmış toplam 19 araştırma incelenmiştir. Çalışmada, nitel araştırma yöntemlerinden doküman analizi tekniği kullanılmış, incelenen araştırmalar betimsel olarak analiz edilmiştir. Betimsel analiz bulguları incelendiğinde incelenen araştırmaların \%52,63’ü zihin yetersizliğe sahip 7-22 yaş arası deneklerle yapıldığı ve araştırmaların \%36,84'ünde eş zamanlı ipucuyla öğretim yönteminin kullanıldığ görülmüştür. Uygulamaların çoğunlukla deneklerin öğrenim gördükleri sınıflarda yapıldığı, incelenen 19 araştırmanın hepsinde verileri toplamak için beceri analizi kaydı tekniği kullanıldığı ve \%36,84'ünde sosyal geçerliğe ilişkin veri toplandığı bulgulanmıştır. Yapılan araştırmalara katılan deneklerin kazandırılmak istenen hedef becerileri kazandığı görülmüştür.

Anahtar sözcükler: özel gereksinimli birey, serbest zaman, serbest zaman becerisi, doküman analizi

Atıf:

Çay, E. (2019). Özel gereksinimli bireylere serbest zaman becerilerinin öğretimine yönelik yapılan araştırmaların incelenmesi. Pamukkale Üniversitesi Eğitim Fakültesi Dergisi, 47, 439-456. doi: $10.9779 /$ pauefd.482383

\footnotetext{
* Özel Eğitim Bilim Uzman1, Millî Eğitim Bakanlı̆̆ı, ORCiD: 0000-0002-1199-3939, evgincay35@ gmail.com
} 


\begin{abstract}
Leisure time is defined as the remaining time period after fulfilling duties and responsibilities, which reinforces personal development, makes individuals happy and help them spend their time efficiently. Since it is important for individuals with special needs to spend their leisure time in a sterling and efficient way, a plenty of research in the literature has focused on teaching leisure time skills to such individuals. In this study, 19 studies about teaching leisure time skills to individuals with special needs which were conducted in Turkey and abroad and published in refereed journals between 2005 and 2016 were investigated. Among qualitative research methods, document analysis technique was adopted and those 19 studies were analyzed descriptively in this study. Findings from the descriptive analysis revealed that $52.63 \%$ of the studies had been conducted with intellectual disability subjects aged 7-22 and simultaneous prompting was employed as the teaching method in $36.84 \%$ of the studies. It was also found out that applications were mostly run in subjects' classrooms, skills analysis recording technique was used to collect data in all of the studies, and the collected data was about social validity in $36.84 \%$ of those studies.
\end{abstract}

Keywords: İndividual with special needs, Leisure time, Leisure time skill, Document analysis

\title{
Cited:
}

Çay, E. (2019). review of research on the teaching of leisure time skills to individuals with special needs. Pamukkale Üniversitesi Ĕgitim Fakültesi Dergisi, 47, 439-456. doi: 10.9779/pauefd.482383 


\section{Giriș}

Alan yazında serbest zaman terimiyle ilgili birden fazla tanım yapılmaktadır. Serbest zaman, kişinin hiçbir baskı altında olmadan günlük görevlerini yerine getirdikten sonra kendi isteğiyle kendini eğlendirdiği, mutlu olduğu ve kendini yönetebildiği zaman olarak tanımlanmaktadır (Argan, 2013; Önder, 2003). Başka bir ifade ile serbest zaman, kişinin bireysel ve zorunlu ihtiyaçlarını karşıladıktan sonra kendine kalan zaman olarak ifade edilmektedir (Mull, Bayless, Ross ve Jamieson, 1997;Torkildsen, 2005). Zamanı kullanma açısından ele alındığında ise bireyin herhangi bir işle meşgul olmadığı zaman ve çalışma dışı yani serbest zaman olarak ele alındığı görülmektedir. Çalışma zamanı, bireyin üretimde bulunduğu, bununla ilgili eylem ve hareketlerini içerirken (Aytaç, 2002), çalışma dişı zaman yani serbest zaman ise bireyin kendisinden beklenen görev ve sorumlulukları yerine getirdikten sonra herhangi bir zorlama olmadan kişisel gelişimini destekleyen etkinliklere katıldığı, eğlenerek güzel vakit geçirdiği zaman dilimi olarak tanımlanabilir.

Serbest zamanın, bireylerin eğlenmelerine ve hoş vakit geçirmelerine yardımcı olmak, bireyin hoşuna giden etkinlikleri sağlamasının yanında bireyi dert ve sıkıntılarından bir nebze de olsa uzaklaştırması, ruhen ve bedenen dinlendirmesi, günlük yaşamı monotonluktan kurtarıp kendisine uğraş edinmesini dolayısıyla vaktini verimli geçirmesi, iş hayatının getirdiği stres, sıkıntıyı azaltmaya yardımcı olması gibi özellikleri vardır ( Hacıŏlu, Gökdeniz ve Dinç, 2009).

Normal gelişim gösteren bireyler serbest zamanlarını nasıl değerlendireceğini planlayabilirken, özel gereksinimli bireyler için ise yönlendirme ya da eğitim gerekebilmektedir. $\mathrm{Bu}$ serbest zaman eğitimi bir süreç olduğundan bu süreçte bireysel farklılıklar dikkate alınarak planlama ve değerlendirme yapılmalıdır (Mosston ve Ashworth, 2000). Özel gereksinimli bireyler, serbest zaman eğitim süreci boyunca kendilerini eğlendirecek ve kaliteli zaman geçirebilecekleri etkinlik ve becerileri öğrenecekleri için bu süreç bu tür bireyler için önemli görülmektedir (Schleien, Meyer, Heyne ve BielBrandt, 1995; Stumbo, 1992). Bu süreç içinde öğretilecek olan etkinlik ve beceriler özel gereksinimli bireylerin öğrenme düzeylerine uygun olması gerekmektedir. Özel gereksinimli bireylerin öğrenme düzeylerine göre seçilen etkinlik ve beceriler, bireyin sosyalleşme, yeni ve farklı becerilerin öğrenilmesinde (Trainor, Delfabbro, Anderson ve Winefield, 2009) önemli görülmekle birlikte; bu tür becerileri öğrenen bireylerin daha fazla yaşam doyumuna sahip oldukları ifade edilmektedir (Lustyk, Widman, Paschane ve Olson, 2004).

$\mathrm{Bu}$ süreç içinde bireysel farklılıklar dikkate alınarak hazırlanan etkinlik ve beceriler çocuklara sosyal, duygusal, psikolojik bakımdan fayda sağladığı gibi kabul gören davranışların gelişmesine, çocuğun sosyal çevresiyle olan etkileşimine katkı sağlamaktadır. Ayrıca bu etkinlik ve becerilerin planlanarak uygulanması grup eğitiminde çocuğun arkadaşlarıyla bütünleşmesine, özel gereksinimi olan öğrencilerin engel türünden ziyade yapabildiklerine odaklandığ 1 için önemlidir (Sucuoğlu, 2009). Yukarıda belirtilenlerin yanı sıra serbest zaman beceri ve etkinlikleri gelişimsel yetersizliği olan ve/veya olmayan tüm çocukları yaşama hazırlaması (MEGEP, 2008) bakımından önemli görülmektedir.

Alan yazında özel gereksinimli bireylerin serbest zaman ve serbest zaman becerilerinin öğretimine yönelik yapılan çalışmalara (Aslan ve Eratay, 2009; Chan, Lambdin, Laarhoven ve Johnson, 2013; Çankaya ve Eratay, 2011; Çay ve Özbey, 2016; Dimaya, Reeve ve Reeve, 2010; 
Eldeniz-Çetin ve Çay, 2016; Gökmen, Tekinarslan ve Çifci-Tekinarslan, 2014; Hammond, Whatley, Ayres ve Gast, 2010; Kurt, 2006; Kagohara, 2011; Kagohara, Sigafoos, Achmadi, Meer, Reilly ve Lancioni, 2011; Malone, Miller, Schaefer, Jimenez, Page ve Sabielny, 2016; Seward, Schuster, Ault, Collins ve Hall, 2014; Vuran, 2008; Y1lmaz, Birkan, Konukman ve Erkan, 2005; Yanardağ, Birkan, Yılmaz, Konukman, Ağbuğa ve Lieberman, 2011) rastlamak mümkündür.

Aslan ve Eratay (2009), zihinsel yetersizliği olan öğrencilere pul işleme becerisini; Chan ve ark. (2013), gelişimsel yetersizliği olan bireylere resim boyama, müzik dinleme ve fotoğraf çekme becerilerinin; Çankaya ve Eratay (2011), zihinsel yetersizliği olan öğrencilere haroşa örgü örme becerisini; Çay ve Özbey (2016), zihinsel yetersizliği olan öğrencilere gitarla ritim atma becerisini; Dimaya ve ark. (2010), otizm spektrum bozukluğu olan bireylere video oyunu oynama becerisini; Eldeniz-Çetin ve Çay (2016), zihinsel yetersizliği olan bireylere bowling oynama becerisini; Gökmen ve ark. (2014), zihinsel yetersizliği olan bireylere bilgisayarda eğitsel cd izleme becerini; Hammond ve ark. (2010), zihinsel yetersizliği olan bireylere iPod kullanma becerisini; Kurt (2006), otizm spektrum bozukluğu olan öğrencilere zincirleme serbest zaman becerilerini; Kagohara (2011), gelişimsel yetersizliği olan bireylere I pod kullanma becerisini; Kagohara ve ark. (2011), gelişimsel yetersizliği olan bireylere I pod touch kullanma becerisini; Malone ve ark. (2016), ağır yetersizliği olan bireylere basketbol, dart, puzzle, domino gibi serbest zaman becerilerini; Seward ve ark. (2014), zihinsel yetersizliği olan bireylere kağıt oyunu oynama becerisini; Vuran (2008), çalışmasında otizm spektrum bozukluğu olan öğrencilere kilden sepet yapma becerisini; Y1lmaz ve ark. (2005), otizm spektrum bozukluğu olan öğrencilere yüzme havuzunda su oyunu becerilerini; Yanardağ ve ark. (2011), otizm spektrum bozukluğu olan bireylere spor salonunda temel tenis becerilerini öğretmeyi hedeflemişlerdir.

Yapılan literatür taraması sonucunda özel gereksinimli bireylere serbest zaman ve serbest zaman becerilerinin kazandırılmasına yönelik araştırmaların yapıldığı görülmektedir. Yapılan bu çalışmalarda kazandırılmak istenen hedef beceriler tek denekli araştırma yöntemleri kullanılarak deneklere kazandırılmıştır. Özel gereksinimli bireylere serbest zaman ve serbest zaman becerilerinin öğretildiği çalışmaları bir bütün olarak ele alıp kendi içinde değerlendirip analiz etmek ve serbest zaman becerilerine yönelik yapılan çalışmaları betimlemek için bu çalışmanın yapılmasına gereksinim duyulmuştur. Bu çalışmanın yapılmasıyla alan yazına katkı sağlayacağ 1 düşünülmektedir. Buradan hareketle bu çalışmada özel gereksinimli bireylere serbest zaman ve serbest zaman becerilerine yönelik 2005-2018 yılları arasında yurt içi ve yurt dışında yapılan çalışmaları incelemek, yapılan araştırmaları çeşitli değişkenler açısından betimlemek amaçlanmıştır.

\section{Yöntem}

Çalışmada, özel gereksinimli bireylere serbest zaman becerilerinin kazandırılmasına yönelik yapılan araştırmalar betimsel analiz kullanılarak incelenmiştir. Greenhalgh (1997)' a göre betimsel analiz bir başka ifadeyle sistematik değerlendirme, belli bir konuda yapılmış araştırmaların kendi içinde çeşitli özellikleri dikkate alınarak incelenmesi ve bu inceleme neticesinde betimsel olarak özetlenmesi olup birincil çalışmaların bir özeti olarak da ifade edilebilir. Betimsel analiz; alan yazın taraması ya da incelemesi, sistematik derleme ve gözden 
geçirme olarak da alan yazında ifade edildiği görülmektedir (Yücesoy-Özkan ve Sönmez, 2011).

Araştırma kapsamına alınan çalışmalar bazı kriterler göz önüne alınarak seçilmiştir: a) 2005-2018 y1lları arasında eğitim ve özel eğitim ile ilgili uluslararası hakemli dergilerde yayınlanmış olması, b) özel gereksinimli bireylerle çalışılmış olması, c) tek denekli araştırma yönteminin kullanılmış olması, d) serbest zaman becerilerine yönelik yapılmış olmasıdır. Alan yazında serbest zaman becerileri ile iş becerileri bazı durumlarda karışabilmektedir. Bu durumda makalenin problem durumu, önem ve tartışma bölümlerinde öğretilen becerinin kullanım amacı yani para kazanma ve meslek edinme ise iş ve meslek becerisi olarak, boş zamanını değerlendirme ve haz alma ise serbest zaman olarak ele alınmıştır. İkisine birden vurgu yapan araştırmalara da yer verilmiştir. Bu kriterleri karşılayan yurt içinde ve yurt dışında toplam 19 çalışmaya rastlanmıştır.

Araştırma kapsamında olan çalışmalara ulaşmak için google akademik, ERIC veri tabanlarında tam metin olarak yayınlanmış makaleler taranmıştır. Tarama serbest zaman (leisure time), serbest zaman becerileri (leisure time skills), yetersizlik ve serbest zaman (disabilities and leisure time), yetersizlik ve serbest zaman becerileri (disabilities and leisure time skills), özel gereksinimli birey ve serbest zaman (individuals with special needs and leisure time) anahtar sözcükleri taranarak yapılmıştır.

\section{Verilerin analizi (Betimsel analiz süreci)}

Araştırma kapsamına alınan çalışmalar numaralandırılmış ve a) yetersizlik türü, b) kullanılan yöntem, c) uygulama ortamı, d) hedef davranış, e) veri toplama tekniği, f) araştırma modeli, g) güvenirlik verileri, h) sosyal geçerlik bakımından tablo1'de; deneklerin özellikleri (yaş, cinsiyet ve yetersizlik türü) bakımından tablo2'de değerlendirilmiştir. Tablo1'de belirtilen kategorilere ilişkin bilgiler ayrıntılı bir şekilde araştırmanın tartışma bölümünde yorumlanmış ve ilgili araştırmalarla desteklenmiştir. Değerlendirme sürecinde ilk önce yukarıda bahsedilen kategoriler dikkate alınarak form hazırlanmıştır. Ayrıca araştırma kapsamına alınan çalışmaların \%30'u (n=6) yansız atama yoluyla seçilerek özel eğitim alanında akademik çalışmalar yapan ve yetersizliği olan bireylere serbest zaman becerileri öğretimi konusunda bilgiye ve çalışmalara sahip bir uzman tarafından güvenirlik çalışması yapılmıştır. Güvenirlik çalışmasının sonucu (Görüş Birliği / Görüş Birliği + Görüş Ayrılığ1 x 100) formülü kullanılarak hesaplanmıştır. Değerlendiriciler arası güvenirlik \% 100 olarak hesaplanmıştır. Güvenirlik belirlendikten sonra formlarda yer alan çalışmalara ilişkin bilgiler Excel programına kaydedilmiş ve frekans ve yüzde hesaplamaları yapılmıştır.

\section{Bulgular}

Bu bölümde araştırma kapsamına alınan çalışmalara yönelik deneklerin yetersizlik türü, yöntem, ortam, kazandırılmak istenen hedef davranışlar, veri toplama teknikleri, araştırma modelleri, güvenirlik ve sosyal geçerlik ile ilgili veriler tablol'de verilmiştir. Bu özellikler aşağıda ayrıntılı olarak açıklanmıştır. Deneklerin özelliklerine (yaş, cinsiyet, yetersizlik türü) ise tablo 2'de ayrıntılı olarak yer verilmiştir. 
Tablo 1 Serbest Zaman Becerilerine Yönelik Yapılan Araştırmaların Özellikleri

\begin{tabular}{|c|c|c|c|c|c|c|c|c|c|}
\hline Z & 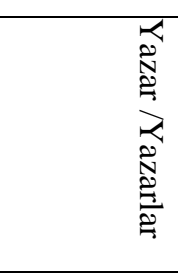 & 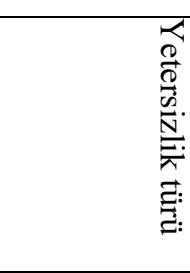 & 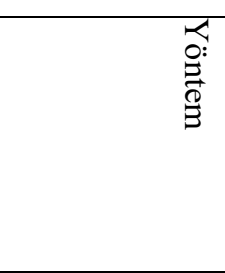 & $\begin{array}{l}\stackrel{0}{Z} \\
\stackrel{\vec{\Xi}}{\Xi}\end{array}$ & 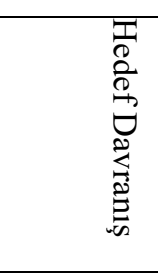 & 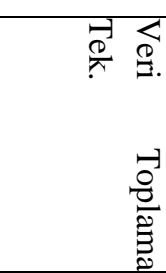 & 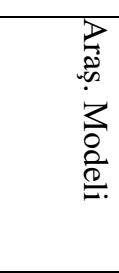 & 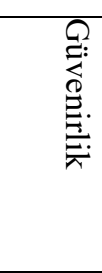 & 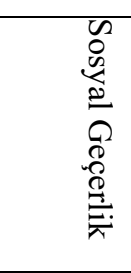 \\
\hline 1 & $\begin{array}{l}\text { Yilmaz, } \\
\text { Birkan, } \\
\text { Konukman } \\
\text { ve Erkan, } \\
2005\end{array}$ & $\begin{array}{l}\text { Otizm } \\
\text { spektrum } \\
\text { bozukluğu }\end{array}$ & $\begin{array}{l}\text { Sabit bekleme } \\
\text { süreli öğretim }\end{array}$ & $\begin{array}{l}\text { Yüzme } \\
\text { havuzu }\end{array}$ & $\begin{array}{l}\text { Su oyun } \\
\text { becerileri }\end{array}$ & $\begin{array}{l}\text { Beceri } \\
\text { analizi }\end{array}$ & YEÇY & $\begin{array}{l}\text { GAG } \\
\mathrm{UG}\end{array}$ & - \\
\hline 2 & $\begin{array}{l}\text { Yücesoy- } \\
\text { Özkan ve } \\
\text { Gürsel, } \\
2006\end{array}$ & $\begin{array}{l}\text { Zihinsel } \\
\text { yetersizlik }\end{array}$ & $\begin{array}{l}\text { Eşzamanlı } \\
\text { ipucuyla } \\
\text { öğretim }\end{array}$ & okul & $\begin{array}{l}\text { Fotokopi } \\
\text { çekme }\end{array}$ & $\begin{array}{l}\text { Beceri } \\
\text { analizi }\end{array}$ & YEÇY & $\begin{array}{l}\text { GAG } \\
\mathrm{UG}\end{array}$ & $\begin{array}{l}\text { Denek } \\
\text { görüşle } \\
\text { ri }\end{array}$ \\
\hline 3 & $\begin{array}{l}\text { Vuran, } \\
2008\end{array}$ & $\begin{array}{l}\text { Otizm } \\
\text { spektrum } \\
\text { bozukluğu }\end{array}$ & $\begin{array}{l}\text { İpucunun } \\
\text { giderek } \\
\text { azaltılması }\end{array}$ & $\begin{array}{l}\text { Özel } \\
\text { özel } \\
\text { eğitim } \\
\text { merkez } \\
\text { i }\end{array}$ & $\begin{array}{l}\text { Kilden } \\
\text { sepet } \\
\text { yapma }\end{array}$ & $\begin{array}{l}\text { Beceri } \\
\text { analizi }\end{array}$ & YDÇY & $\begin{array}{l}\text { GAG } \\
\mathrm{UG}\end{array}$ & $\begin{array}{l}\text { Anne, } \\
\text { baba ve } \\
\text { öğretm } \\
\text { en } \\
\text { görüşle } \\
\text { ri } \\
\end{array}$ \\
\hline 4 & $\begin{array}{l}\text { Aslan ve } \\
\text { Eratay, } \\
2009\end{array}$ & $\begin{array}{l}\text { Zihinsel } \\
\text { yetersizlik }\end{array}$ & $\begin{array}{l}\text { Eşzamanlı } \\
\text { ipucuyla } \\
\text { öğretim }\end{array}$ & Sinif & $\begin{array}{l}\text { Pul } \\
\text { işleme }\end{array}$ & $\begin{array}{l}\text { Beceri } \\
\text { analizi }\end{array}$ & YEÇY & $\begin{array}{l}\text { GAG } \\
\mathrm{UG}\end{array}$ & - \\
\hline 5 & $\begin{array}{l}\text { Blum- } \\
\text { Dimaya, } \\
\text { Reeve ve } \\
\text { Reeve ve } \\
\text { Hoch, } \\
2010\end{array}$ & $\begin{array}{l}\text { Otizm } \\
\text { spektrum } \\
\text { bozukluğu }\end{array}$ & $\begin{array}{l}\text { Video model } \\
\text { ve etkinlik } \\
\text { çizelgesi }\end{array}$ & $\begin{array}{l}\text { Bireyse } \\
\text { l eğitim } \\
\text { sınıfı }\end{array}$ & $\begin{array}{l}\text { Video } \\
\text { oyunu } \\
\text { oynama }\end{array}$ & $\begin{array}{l}\text { Beceri } \\
\text { analizi }\end{array}$ & YDÇY & $\begin{array}{l}\text { GAG } \\
\mathrm{UG}\end{array}$ & $\begin{array}{l}\text { Psikolo } \\
\text { ji lisans } \\
\text { öğrenci } \\
\text { görüşle } \\
\text { ri }\end{array}$ \\
\hline 6 & $\begin{array}{l}\text { Hammond, } \\
\text { Whatley, } \\
\text { Ayres ve } \\
\text { Gast, } 2010\end{array}$ & $\begin{array}{l}\text { Zihinsel } \\
\text { yetersizlik }\end{array}$ & Video model & $\begin{array}{l}\text { Bireyse } \\
1 \text { eğitim } \\
\text { sınıfı }\end{array}$ & $\begin{array}{l}\text { pod } \\
\text { kullanımı }\end{array}$ & $\begin{array}{l}\text { Beceri } \\
\text { analizi }\end{array}$ & YDÇY & $\begin{array}{l}\text { GAG } \\
\mathrm{UG}\end{array}$ & $\begin{array}{l}\text { Öğretm } \\
\text { en ve } \\
\text { terapist } \\
\text { görüşle } \\
\text { ri }\end{array}$ \\
\hline 7 & $\begin{array}{l}\text { Kagohara, } \\
2011\end{array}$ & $\begin{array}{l}\text { Gelişimsel } \\
\text { yetersizlik }\end{array}$ & $\begin{array}{l}\text { Video model } \\
\text { ve ipucunun } \\
\text { giderek } \\
\text { azaltılması }\end{array}$ & Sinif & $\begin{array}{l}\text { I pod } \\
\text { kullanma }\end{array}$ & $\begin{array}{l}\text { Beceri } \\
\text { analizi }\end{array}$ & YDÇY & $\begin{array}{l}\text { GAG } \\
\mathrm{UG}\end{array}$ & - \\
\hline 8 & $\begin{array}{l}\text { Kagohara, } \\
\text { Sigafoos, } \\
\text { Achmadi, } \\
\text { Meer, } \\
\text { Reilly ve }\end{array}$ & $\begin{array}{l}\text { Gelişimsel } \\
\text { yetersizlik }\end{array}$ & Video model & Sinif & $\begin{array}{l}\text { I pod } \\
\text { touch } \\
\text { kullanma }\end{array}$ & $\begin{array}{l}\text { Beceri } \\
\text { analizi }\end{array}$ & YDÇY & $\begin{array}{l}\text { GAG } \\
\mathrm{UG}\end{array}$ & - \\
\hline
\end{tabular}


Özel Gereksinimli Bireylere Serbest Zaman Becerilerinin Öğretimine Yönelik Yapılan Araştırmaların

\begin{tabular}{|c|c|c|c|c|c|c|c|c|c|}
\hline & $\begin{array}{l}\text { Lancioni, } \\
2011\end{array}$ & & & & & & & & \\
\hline 9 & $\begin{array}{l}\text { Yanardağ, } \\
\text { Birkan, } \\
\text { Y1lmaz, } \\
\text { Konukman } \\
, \quad \text { Ağbuğa } \\
\text { ve } \\
\text { Lieberman, } \\
2011\end{array}$ & $\begin{array}{l}\text { Otizm } \\
\text { spektrum } \\
\text { bozukluğu }\end{array}$ & $\begin{array}{l}\text { İpucunun } \\
\text { giderek } \\
\text { azalt1lmas1 }\end{array}$ & $\begin{array}{l}\text { Spor } \\
\text { salonu }\end{array}$ & $\begin{array}{l}\text { Temel } \\
\text { tenis } \\
\text { becerileri }\end{array}$ & $\begin{array}{l}\text { Beceri } \\
\text { analizi }\end{array}$ & YEÇY & $\begin{array}{l}\text { GAG } \\
\text { UG }\end{array}$ & - \\
\hline 10 & $\begin{array}{l}\text { Çankaya } \\
\text { ve Eratay, } \\
2011\end{array}$ & $\begin{array}{l}\text { Zihinsel } \\
\text { yetersizlik }\end{array}$ & $\begin{array}{l}\text { Eşzamanlı } \\
\text { ipucuyla } \\
\text { öğretim }\end{array}$ & Sinif & $\begin{array}{l}\text { Haroşa } \\
\text { örgü } \\
\text { örme }\end{array}$ & $\begin{array}{l}\text { Beceri } \\
\text { analizi }\end{array}$ & YEÇY & $\begin{array}{l}\text { GAG } \\
\text { UG }\end{array}$ & - \\
\hline 11 & $\begin{array}{l}\text { Chan, } \\
\text { Lambdin, } \\
\text { Laarhoven } \\
\text { ve } \\
\text { Johnson, } \\
2013\end{array}$ & $\begin{array}{l}\text { Gelişimsel } \\
\text { yetersizlik }\end{array}$ & $\begin{array}{l}\text { Video ipucu } \\
\text { ve ipucunun } \\
\text { giderek } \\
\text { arttırılması }\end{array}$ & $\begin{array}{l}\text { Resim } \\
\text { odas1 }\end{array}$ & $\begin{array}{l}\text { Resim } \\
\text { boyama, } \\
\text { müzik } \\
\text { dinleme } \\
\text { ve } \\
\text { fotoğraf } \\
\text { çekme }\end{array}$ & $\begin{array}{l}\text { Beceri } \\
\text { analizi }\end{array}$ & YDÇY & $\begin{array}{l}\text { GAG } \\
\text { UG }\end{array}$ & - \\
\hline 12 & $\begin{array}{l}\text { Carlile, } \\
\text { Reeve, } \\
\text { Reeve ve } \\
\text { Debar, } \\
2013\end{array}$ & $\begin{array}{l}\text { Otizm } \\
\text { spektrum } \\
\text { bozukluğu }\end{array}$ & $\begin{array}{l}\text { Etkinlik } \\
\text { çizelgesi }\end{array}$ & - & $\begin{array}{l}\text { Serbest } \\
\text { zaman } \\
\text { Etkinlikl } \\
\text { er için i- } \\
\text { podta } \\
\text { etkinlik } \\
\text { çizelgesi } \\
\text { nin } \\
\text { kullanımı }\end{array}$ & $\begin{array}{l}\text { Beceri } \\
\text { analizi }\end{array}$ & YDÇY & $\begin{array}{l}\text { GAG } \\
\text { UG }\end{array}$ & $\begin{array}{l}\text { Lisans } \\
\text { öğrenci } \\
\text {, akran, } \\
\text { eğitimc } \\
i \text {, } \\
\text { persone } \\
1\end{array}$ \\
\hline 13 & $\begin{array}{l}\text { Seward, } \\
\text { Schuster, } \\
\text { Ault, } \\
\text { Collins ve } \\
\text { Hall, } 2014\end{array}$ & $\begin{array}{l}\text { Zihinsel } \\
\text { yetersizlik }\end{array}$ & $\begin{array}{l}\text { Eşzamanlı ve } \\
\text { sabit bekleme } \\
\text { süreli }\end{array}$ & $\begin{array}{l}\text { Bireyse } \\
1 \text { eğitim } \\
\text { sinıfi }\end{array}$ & $\begin{array}{l}\text { Kağıt } \\
\text { oyunu }\end{array}$ & $\begin{array}{l}\text { Beceri } \\
\text { analizi }\end{array}$ & YDÇY & $\begin{array}{l}\text { GAG } \\
\text { UG }\end{array}$ & - \\
\hline 14 & $\begin{array}{l}\text { Chan, } \\
\text { Lambdin, } \\
\text { Graham, } \\
\text { Fragale ve } \\
\text { Davis, } \\
2014\end{array}$ & $\begin{array}{l}\text { Zihinsel } \\
\text { yetersizlik }\end{array}$ & $\begin{array}{l}\text { Etkinlik } \\
\text { çizelgesi }\end{array}$ & $\begin{array}{l}\text { Çalışm } \\
\text { a odası }\end{array}$ & $\begin{array}{l}\text { Video } \\
\text { oyunu }\end{array}$ & $\begin{array}{l}\text { Beceri } \\
\text { analizi }\end{array}$ & YDÇY & $\begin{array}{l}\text { GAG } \\
\text { UG }\end{array}$ & - \\
\hline 15 & $\begin{array}{l}\text { Gökmen, } \\
\text { Tekinarsla } \\
\text { n ve Çifci- } \\
\text { Tekinarsla } \\
\text { n, } 2014\end{array}$ & $\begin{array}{l}\text { Zihinsel } \\
\text { yetersizlik }\end{array}$ & $\begin{array}{l}\text { Eşzamanlı } \\
\text { ipucu }\end{array}$ & $\begin{array}{l}\text { Bireyse } \\
1 \text { eğitim } \\
\text { sinıfi }\end{array}$ & $\begin{array}{l}\text { Bilgisaya } \\
\text { rda } \\
\text { eğitsel cd } \\
\text { izleme }\end{array}$ & $\begin{array}{l}\text { Beceri } \\
\text { analizi }\end{array}$ & YEÇY & $\begin{array}{l}\text { GAG } \\
\text { UG }\end{array}$ & $\begin{array}{l}\text { Anne } \\
\text { görüşle } \\
\text { ri }\end{array}$ \\
\hline 16 & $\begin{array}{l}\text { Aykut, } \\
\text { Emecen, }\end{array}$ & $\begin{array}{l}\text { Zihinsel } \\
\text { yetersizlik }\end{array}$ & Video ipucu & Sinif & $\begin{array}{l}\text { Portakal } \\
\text { soyma, }\end{array}$ & $\begin{array}{l}\text { Beceri } \\
\text { analizi }\end{array}$ & YEÇY & $\begin{array}{l}\text { GAG } \\
\text { UG }\end{array}$ & $\begin{array}{l}\begin{array}{l}\text { Öğretm } \\
\text { en }\end{array} \\
\end{array}$ \\
\hline
\end{tabular}




\begin{tabular}{|c|c|c|c|c|c|c|c|c|c|}
\hline & $\begin{array}{l}\text { Dayı ve } \\
\text { Karasu, } \\
2014\end{array}$ & & & & $\begin{array}{l}\text { teğel } \\
\text { yapma ve } \\
\text { kağıttan } \\
\text { köpek } \\
\text { yapma }\end{array}$ & & & & $\begin{array}{l}\text { görüşle } \\
\text { ri }\end{array}$ \\
\hline 17 & $\begin{array}{l}\text { Eldeniz- } \\
\text { Çetin ve } \\
\text { Çay, } 2016\end{array}$ & $\begin{array}{l}\text { Zihinsel } \\
\text { yetersizlik }\end{array}$ & $\begin{array}{l}\text { Eşzamanlı } \\
\text { ipucu }\end{array}$ & $\begin{array}{l}\text { Okul, } \\
\text { bowlin } \\
\mathrm{g} \\
\text { salonu }\end{array}$ & $\begin{array}{l}\text { Bowling } \\
\text { oynama }\end{array}$ & $\begin{array}{l}\text { Beceri } \\
\text { analizi }\end{array}$ & YEÇY & $\begin{array}{l}\text { GAG } \\
\text { UG }\end{array}$ & - \\
\hline 18 & $\begin{array}{l}\text { Çay ve } \\
\text { Özbey, } \\
2016\end{array}$ & $\begin{array}{l}\text { Zihinsel } \\
\text { yetersizlik }\end{array}$ & $\begin{array}{l}\text { Eşzamanlı } \\
\text { ipucu }\end{array}$ & Sinif & $\begin{array}{l}\text { Gitarla } \\
\text { ritim } \\
\text { atma }\end{array}$ & $\begin{array}{l}\text { Beceri } \\
\text { analizi }\end{array}$ & YEÇY & $\begin{array}{l}\text { GAG } \\
\text { UG }\end{array}$ & - \\
\hline 19 & $\begin{array}{l}\text { Cannella- } \\
\text { Malone, } \\
\text { Miller, } \\
\text { Schaefer, } \\
\text { Jimenez, } \\
\text { Page ve } \\
\text { Sabielny, } \\
2016\end{array}$ & $\begin{array}{l}\text { Ağır } \\
\text { yetersizlik }\end{array}$ & Video ipucu & Sinif & $\begin{array}{l}\text { Basketbo } \\
1, \text { dart, } \\
\text { hava } \\
\text { roketi, } \\
\text { balonlu } \\
\text { sakiz, } \\
\text { domino, } \\
\text { puzzle, } \\
\text { selfi }\end{array}$ & $\begin{array}{l}\text { Beceri } \\
\text { analizi }\end{array}$ & YDÇY & $\begin{array}{l}\text { GAG } \\
\text { UG }\end{array}$ & - \\
\hline
\end{tabular}

YEÇY: Yoklama evreli çoklu yoklama YDÇY: Yoklama denemeli çoklu yoklama GAG: Gözlemciler arası güvenirlik UG: Uygulama güvenirliği

\section{Deneklerin Yetersizlik Türleri}

İncelenen 19 çalışmada farklı yetersizliğe sahip deneklerle araştırmalar yapıldığı ve bu yetersizlik türlerinin zihinsel yetersizlik, gelişimsel yetersizlik, ağır yetersizlik ve otizm spektrum bozukluğu olduğu görülmektedir. İncelenen çalışmaların \%26,31'i $(n=5)$ otizm spektrum bozukluğu (Y1lmaz ve ark., 2005; Vuran, 2008; Dimaya ve ark., 2010; Yanardağ ve ark., 2011 ve Carlile ve ark., 2013), \%52,63’ü (n=10) zihinsel yetersizlik(Yücesoy-Özkan ve Gürsel, 2006; Aslan ve Eratay, 2009; Hammond ve ark., 2010; Çankaya ve Eratay, 2011; Seward ve ark., 2014; Chan ve ark., 2014; Gökmen ve ark., 2014; Aykut ve ark., 2014; EldenizÇetin ve Çay, 2016; Çay ve Özbey, 2016), \%15,78'i (n=3) gelişimsel yetersizlik(Kagohara, 2011; Kagohara ve ark., 2011 ve Chan ve ark., 2013) ve \%5,26’s1 (n=1) ağır yetersizliğe(Malone ve ark., 2016) sahip bireylerle yapılmıştır.

\section{Deneklerin Özellikleri}

Araştırmaya dahil edilen çalışmalarda yer alan denekler yaş, cinsiyet ve yetersizlik türlerine göre incelenmiş, tablo2'de ayrıntılı olarak verilmiştir. 
Tablo2. Denek özellikleri

\begin{tabular}{|c|c|c|}
\hline Denek özellikleri & $\mathrm{f}$ & $\%$ \\
\hline \multicolumn{3}{|l|}{ Yaş } \\
\hline $7-9$ & 8 & 11,94 \\
\hline $8-12$ & 4 & 5,97 \\
\hline $9-12$ & 4 & 5,97 \\
\hline $11-13$ & 3 & 4,47 \\
\hline $12-14$ & 3 & 4,47 \\
\hline $12-21$ & 9 & 13,43 \\
\hline $14-17$ & 4 & 5,97 \\
\hline $15-16$ & 3 & 4,47 \\
\hline \multicolumn{3}{|l|}{ Tablo2'nin devamı } \\
\hline Denek özellikleri & $\mathrm{f}$ & $\%$ \\
\hline \multicolumn{3}{|l|}{ Yaş } \\
\hline $15-19$ & 3 & 4,47 \\
\hline $15-20$ & 8 & 11,94 \\
\hline $16-23$ & 3 & 4,47 \\
\hline $17-18$ & 6 & 8,95 \\
\hline $19-22$ & 3 & 4,47 \\
\hline $21-23$ & 2 & 2,98 \\
\hline $33-51$ & 3 & 4,47 \\
\hline 35 & 1 & 1,49 \\
\hline & $1=6$ & \\
\hline \multicolumn{3}{|l|}{ Cinsiyet } \\
\hline Erkek & 43 & 64,17 \\
\hline $\mathrm{K}_{1 \mathrm{z}}$ & 24 & 35,82 \\
\hline & $1=6$ & \\
\hline \multicolumn{3}{|l|}{ Yetersizlik türleri } \\
\hline Zihinsel yetersizlik & 33 & 49,25 \\
\hline Otizm spektrum bozukluğu & 18 & 26,86 \\
\hline Gelişimsel yetersizlik & 7 & 10,44 \\
\hline Ağır yetersizlik & 9 & 13,43 \\
\hline
\end{tabular}

"Çalışmaya katılan toplam denek sayısıdır.

Çalışmalara katılan deneklerin ( $\mathrm{n}=67), \% 11,94$ 'ünün $(\mathrm{n}=8)$ 7-9 yaş arasında olduğu, \%5,97' $\operatorname{sinin}(n=4)$ 8-12 yaş arasında, \%5,97'sinin $(n=4)$ 9-12 yaş arasında, \%4,47'sinin $(n=3)$ 11-13 yaş arasında, \%4,47'sinin $(n=3)$ 12-14 yaş arasında, \%13,43'ünün $(n=9)$ 12-21 yaş arasında, \%5,97'sinin $(\mathrm{n}=4)$ 14-17 yaş arasında, \%4,47'sinin $(\mathrm{n}=3)$ 15-16 yaş arasında, 
$\% 4,47$ 'sinin $(\mathrm{n}=3)$ 15-19 yaş arasında, \%11,94'ünün $(\mathrm{n}=8)$ 15-20 yaş arasında, \%4,47'sinin $(\mathrm{n}=3)$ 16-23 yaş arasında, \%8,95'inin $(\mathrm{n}=6)$ 17-18 yaş arasında, \%4,47'sinin $(\mathrm{n}=3)$ 19-22 yaş arasında, \%2,98'inin $(n=2)$ 21-23 yaş arasında, \%4,47'sinin $(n=3) 33-51$ yaş arasında ve $\% 1,49$ 'unun $(\mathrm{n}=1)$ ise 35 yaşında olduğu görülmektedir. Çalışmalar, deneklerin cinsiyetleri bakımından incelendiğinde; çalışmalara katılan deneklerin \%64,17'sini $(n=43)$ erkekler oluştururken \%35,82'sini ( $\mathrm{n}=24)$ kızlar oluşturmaktadır. Araştırmalarda yer alan deneklerin zihinsel yetersizlik, otizm, gelişimsel yetersizlik ve ağır yetersizlik gibi yetersizlikleri olduğu görülmektedir. Deneklerin \%49,25'inde $(n=33)$ zihinsel yetersizlik görülürken \%26,86'sında $(\mathrm{n}=18)$ otizm spektrum bozukluğu, \%10,44'ünde $(\mathrm{n}=7)$ gelişimsel yetersizlik ve $\% 13,43$ 'ünde $(n=9)$ ağır yetersizlik görülmektedir.

\section{Kullanılan Araştırma Yöntemleri}

İncelenen 19 çalışmada hedef davranışların kazandırılmasında eşzamanlı ipucuyla öğretim, sabit bekleme süreli öğretim, video ipucuyla öğretim, ipucunun giderek azaltılması, video model, etkinlik çizelgesi ve ipucunun giderek arttırılması gibi yöntemlerin kullanıldığı görülmektedir. Kullanılan yöntemler arasında en çok kullanılan yöntemin eşzamanlı ipucuyla öğretim olduğu ve çalışmaların \%36,84'ünde $(\mathrm{n}=7)$ bu yöntemin kullanıldığı görülmektedir. Ayrıca eş zamanlı ipucuyla öğretim yönteminin diğer yanlışsı öğretim yöntemlerinden olan sabit bekleme süreli öğretimle birlikte bir tek araştırmada (Seward, Schuster, Ault, Collins ve Hall, 2014) kullanılmıştır. Çalışmaların \%21,05'inde $(\mathrm{n}=4)$ video model, \%15,78'inde $(\mathrm{n}=3)$ video ipucu, $\% 15,78$ 'inde $(n=3)$ ipucunun giderek azaltılmas1, \%10,52'sinde $(n=2)$ sabit bekleme süreli öğretim ve \%5,26'sında $(\mathrm{n}=1)$ ise ipucunun giderek arttırılması yönteminin kullanıldı̆̆ görülmüştür.

\section{Araştırma Ortamları}

İncelenen çalışmalarda uygulamalar; sınıf, okul, bireysel eğitim sınıfı, yüzme havuzu, özel özel eğitim merkezi, spor salonu, resim odası, bowling salonu, çalışma odası gibi farklı ortamlarda yapılmıştır. Uygulamaların \%36,84'ü $(\mathrm{n}=7)$ deneklerin öğrenim gördüğü sınıflarda, \%10,52'si $(n=2)$ okulda, \%21,05'i $(n=4)$ bireysel eğitim sinıfinda, \%5,26'sı $(n=1)$ yüzme havuzunda, \%5,26's1 ( $\mathrm{n}=1)$ özel özel eğitim merkezinde, \%5,26's1 ( $\mathrm{n}=1)$ spor salonunda, \%5,26's1 (n=1) resim odasında, \%5,26'sı $(\mathrm{n}=1)$ bowling salonu ve \%5,26'sı (n=1) çalışma odasında gerçekleştirilmiştir. Ayrıca incelenen çalışmalarda okul ve bowling salonu gibi ortamların birlikte kullanıldığı çalışmalar (Eldeniz-Çetin ve Çay, 2016) görülmüştür.

\section{Deneklere Kazandırılmak İstenen Hedef Davranışlar}

Araştırma kapsamına alınan çalışmalarda; cd çalar çalıştırma, fotokopi çekme, pul işleme, haroşa örgü örme, bilgisayarda eğitsel cd izleme, portakal soyma, teğel yapma, kağıttan köpek yapma, bowling oynama, gitarla ritim atma, su oyun becerileri, kilden sepet yapma, video oyunu oynama, 1 pod kullanma, temel tenis becerileri, resim boyama, müzik dinleme, fotoğraf çekme, kağıt oyunu, dart oyunu, basketbol, hava roketi, balonlu sakız, domino, puzzle ve selfi çekme gibi becerilerini kazandırmaya yönelik uygulamalar yapılmıştır. Yapılan araştırmaların $(n=19)$, \%15,78'inde (n=3) (Chan ve ark., 2013; Aykut ve ark., 2014; Malone ve ark., 2016) deneklere kazandırılmak istenen birden fazla hedef davranışın birlikte kazandırıldığı görülmüştür. İncelenen araştırmaların $\% 5,26$ 'sında $(\mathrm{n}=1)$ fotokopi çekme becerisi, $\% 5,26$ 'sında su oyun becerileri, \%5,26'sında kilden sepet yapma, \%5,26'sında pul işleme becerisi, \%10,52'sinde 
$(\mathrm{n}=2)$ video oyunu, \%15,78'inde $(\mathrm{n}=3)$ I pod kullanım1, \%5,26'sinda temel tenis becerileri, $\% 5,26$ 'sında haroşa örgü örme becerisi, $\% 5,26$ 'sında resim boyama, müzik dinleme ve fotoğraf çekme becerilerinin birlikte, \%5,26'sında serbest zaman etkinlikleri için iPod'ta etkinlik çizelgesi kullanımı, \%5,26'sında bilgisayarda eğitsel cd izleme, \%5,26'sında portakal soyma, teğel yapma ve kağıttan köpek yapma, \%5,26'sında kağıt oyunu oynama, \%5,26'sında bowling becerisi, \%5,26'sında gitarla ritim atma becerisinin kazandırıldığı görülmüştür.

\section{Araştırmalarda Kullanılan Veri Toplama Teknikleri}

İncelenen 19 araştırmanın hepsinde yani yapılan çalışmaların \%100'ünde (n=19) verilerini toplamak için beceri analizi kaydı tekniği kullanıldığı görülmüştür.

\section{Araştırmalarda Kullanılan Modeller}

Yöntemin etkililiğini belirlemek için araştırma kapsamına dahil edilen araştırmalarda yoklama evreli çoklu yoklama ve yoklama denemeli çoklu yoklama modeli kullanılmıştır. Araştırmaların $\% 47,36$ 'sında $(\mathrm{n}=9)$ yoklama evreli çoklu yoklama modeli, $\% 52,63$ 'ünde $(\mathrm{n}=10)$ ise yoklama denemeli çoklu yoklama modeli kullanıldığı görülmüştür.

\section{Güvenirlik Verileri}

İncelenen çalışmaların \%100'ünde ( $\mathrm{n}=19)$ yani tamamında uygulama güvenirliği ve gözlemciler arası güvenirlik verilerinin birlikte toplandığ1 görülmüştür.

\section{Araştırmalarda Alınan Sosyal Geçerliliğe İlişkin Veriler}

İncelenen 19 araştırmanın \%36,84'ünde $(n=7)$ sosyal geçerliğe ilişkin veri toplandığı görülmüştür. Sosyal geçerlik verisi toplanan çalışmaların \%10,52'sinde $(\mathrm{n}=2)$ sadece annelerin görüşlerine yönelik veriler toplanırken, $\% 5,26$ 'sında $(\mathrm{n}=1)$ ise anne ve baba görüşlerine yönelik verilerin birlikte toplandığı görülmüsstür. Lisans psikoloji bölümü öğrencilerinin görüşlerine araştırmaların \%5,26'sında $(n=1)$ rastlanırken, denek görüşlerine yer veren yalnızca $(n=1)$ bir araştırmaya (Özkan-Yücesoy ve Gürsel, 2006) rastlanmıştır. İncelenen araştırmaların $\% 5,26$ 'sinda $(\mathrm{n}=1)$ öğretmen, \%5,26'sında $(\mathrm{n}=1)$ ise lisans öğrencileri, personel, akran ve eğitimci görüşlerini belirlemek için sosyal geçerlik verisi toplanmıştır. Toplanan sosyal geçerlik verileri bulgularının olumlu olduğu görülmüştür.

\section{Tartışma ve Sonuç}

İnceleme kapsamına alınan 19 araştırmada en fazla $(\% 52,63)$ çalışılan denek grubunun zihinsel yetersizliği olan bireyler olduğu görülmektedir. Diğerleri ise sırasıyla \%26,31'i otizm spektrum bozukluğu, \%5,26's1 ağır yetersizlik ve \%15,78'i gelişimsel yetersizliktir. Dolayısıyla en az çalışılan yetersizlik grubu ağır yetersizliğe sahip deneklerdir. Deneklerin cinsiyet ve yaş aralıkları göz önüne alındığında ise en fazla erkeklerle çalışıldığ 1 ve yaş aralıklarının 7 ile 51 yaş arasında olduğu görülmektedir. Özel gereksinimli bireylerin zamanlarını daha verimli ve kaliteli geçirebilmeleri için serbest zaman eğitimin verilmesi önemli görülmektedir. Bu yüzden ileride serbest zaman ve serbest zaman becerilerinin öğretimine yönelik yapılacak araştırmalarda seçilen deneklerin yaş, cinsiyet ve yetersizlik türleri göz önüne alınması gerektiği düşünülmektedir.

İncelenen araştırmaların çoğunda ( $\mathrm{n}=7)$ eşzamanlı ipucuyla öğretim yönteminin kullanıldığı görülmektedir. Bu yöntemle yapılan araştırmaların bulguları, kazandırılmak istenen 
hedef davranışların denekler tarafından daha kolay öğrenildiğini göstermektedir. Dolayısıyla bu araştırmanın bulguları, alan yazında eşzamanlı ipucuyla yapılan araştırmaların (Yücesoy-Özkan ve Gürsel, 2006; Aslan ve Eratay, 2009; Çankaya ve Eratay, 2011; Seward ve ark., 2014; Gökmen ve ark., 2014; Eldeniz-Çetin ve Çay, 2016; Çay ve Özbey, 2016) bulgularılyla paralellik göstermektedir. Yanlışsız öğretim yöntemlerinden olan eşzamanlı ipucuyla öğretimin uygulama esnasında deneğin hata yapma olasılığını en aza indirdiği ya da ortadan kaldırdığı için deneklerin becerileri daha kolay ve daha çabuk öğrendikleri söylenebilir. Bu yüzden öğretmenlerin kazandırılmak istenen hedef davranışların öğretimi esnasında bu yöntemi seçtikleri düşünülmektedir.

Araştırmanın bulguları, incelenen çalışmaların okul, sınıf, bireysel eğitim sınıfı, resim odası, çalışma odası gibi alışıldık ve deneklerin bulunduğu bilindik ortamlarda yapıldığını göstermektedir. Öğrenilen becerilerin işlevsel olabilmesi ve her durumda, ortam ve kişilerce kullanılabilmesi önemli görülmektedir (Toper-Korkmaz, 2012). Bu yüzden uygulama ve genelleme oturumlarının deneklerin eğitim ortamlarında gerçekleştirilmesi bir sınırlılıktır. İncelenen araştırmaların $(n=19)$ sadece $\% 15,78$ 'inde $(n=3)$ (Yılmaz ve ark., 2005; Yanardağ ve ark., 2011; Eldeniz-Çetin ve Çay, 2016) öğretim sonrasında yapılan oturumlar gerçek ortamında (bowling, spor salonu ve yüzme havuzu) yapılmıştır. Bu açıdan bakıldığında öğretimi ve genellemesi gerçek ortamında yapıldığı bu araştırmalarda denekler kazandırılmak istenen hedef davranışları daha kolay sergilemişlerdir. Deneklerin öğrendikleri becerileri sadece öğrendikleri ortamlarda kullanmakla kalmayıp diğer ortamlara da genelleyebilmeleri denekler açısından önemli görülmektedir. Genelleme oturumlarının doğal ortamda yapılması araştırmanın güçlü yanını ortaya koymaktadır.

Normal gelişim gösteren bireyler kendilerini meşgul edecek etkinlikler bulabilirken özel gereksinimli bireyler bulamayabilir ve zamanlarını verimsiz ve kalitesiz bir şekilde harcayabilirler. İncelenen araştırmalarda özel gereksinimli bireylerin serbest zamanlarını verimli geçirmelerine yardım edecek etkinlik ve becerilerin öğretildiği görülmekte ve kazandırılmak istenen etkinlik ve becerilerin öğretimi özel gereksinimli bireylerin yaşam kalitesini arttıracağından önemli görülmektedir.

Araştırmanın bir diğer bulgusu, incelenen çalışmalarda kazandırılmak istenen beceriler küçük basamaklara bölünmüş ve bu becerilere ilişkin veriler beceri analizi kaydı tekniğiyle toplanmıştır. Küçük basamaklara bölünmüş becerilerin öğretimi yapılırken deneklerin daha az hatayla öğrenmeleri sağlanmıştır. Dolayısıyla denek beceriyi gerçekleştirirken daha az hata yaparak beceriyi öğrenme firsatı bulmuştur. Böylece deneklerin öğrendikleri davranışları daha az unuttukları ve daha çabuk öğrendikleri söylenebilir (Çay, 2017). İncelenen araştırmaların $\% 47,36$ 'sında $(\mathrm{n}=9)$ yoklama evreli çoklu yoklama modeli, \%52,63'ünde $(\mathrm{n}=10)$ ise yoklama denemeli çoklu yoklama modeli kullanıldığı bulgulanmıştır. Yapılan araştırmaların çoğunda yoklama denemeli çoklu yoklama modeli kullanılmıştır. Bunun nedeninin yoklama denemeli çoklu yoklama modelinde çok fazla başlama düzeyi verisi toplanmaması, ara ara alınan deneme oturumlarıyla deneğin çok fazla sıkılmasına imkan vermemesi olabilir. Dolayısıyla bu modelin yapılacak olan ileriki araştırmalarda kullanılması önerilebilir.

Araştırmaların tümünde uygulama güvenirliği ve gözlemciler arası güvenirlik verilerinin birlikte alındığı bulgulanmıştır. Araştırmacının oturumları planladığı gibi uygulayıp uygulamadığını belirlemek ve değerlendirme esnasında yanlılığı ortadan kaldırmak adına 
uygulama ve gözlemciler arası güvenirlik verilerinin alınması önemli görülmektedir. Yapılan çalışmalarda gerek kullanılan yönteme ilişkin gerekse kazandırılmak istenen hedef davranışlara ilişkin sosyal geçerlik verilerinin toplanması yapılan o araştırmanın niteliğine de yansımaktadır. $\mathrm{Bu}$ yüzden araştırmalarda sosyal geçerlik verilerini toplamak için velilerden, ailelerden, lisans öğrencilerinden, akademisyenlerden, personelden, deneklerden ve öğretmenlerden hedef davranışa ve yönteme ilişkin görüşler alındığı görülmektedir. Araştırma kapsamına alınan yedi çalışmada sosyal geçerlik bulgularına rastlanırken diğer 12 çalışmada veri toplanmadığ görülmüştür. Vuran ve Sönmez (2008)'e göre geçerliliği ve güvenirliği sağlanmış başarılı bir çalışmaya yönelik sosyal geçerlik verilerinin toplanması yapılan araştırmanın nitelikli olmasını sağlamaktadır. Bundan dolayı yapılacak olan çalışmalarda sosyal geçerlik verilerinin toplanması önemli görülmektedir.

Araştırma kapsamına dâhil edilen 19 çalı̧̧ma; denek özellikleri, ortam, yöntem, kazandırılmak istenen hedef davranışları, veri toplama teknikleri, modeli, güvenirlik ve sosyal geçerlik verileri bakımından analiz edilerek incelenmiştir. Özel gereksinimli bireylere serbest zaman becerilerinin kazandırılmasına ilişkin 2005-2016 yılları arasında sınırlı sayıda araştırmanın yapıldığı görülmüştür. Özel gereksinimli bireylerin serbest zamanlarını kaliteli ve verimli bir şekilde geçirmelerini, normal gelişim gösteren akranlarıyla sosyalleşmelerini sağlamak için daha çok araştırmanın yapılmasına ihtiyaç duyulmaktadır.

$\mathrm{Bu}$ araştırma serbest zaman ve serbest zaman becerilerine yönelik 2005-2016 yılları arasında yapılmış 19 araştırmayla sınırlıdır. Dolayısıyla; 1) 2005 yılı öncesi yurt dışında yapılmış çalışmalar incelenebilir, 2) kazandırılmak istenen hedef becerilerin öğretiminde farklı yöntemler kullanılabilir, 3) 2005-2016 yılları arasında yurt içi ve yurt dışında sınırlı araştırmaya rastlandığı için daha fazla çalışmanın yapılması önerilebilir, 4) 2005 yılı öncesi yurt içinde serbest zaman becerilerinin öğretimine ilişkin çalışmalar incelenebilir. 


\section{Kaynakça}

Argan M. (Ed.) (2013) Rekreasyon yönetimi. Eskişehir: Anadolu Üniversitesi Web-ofset Tesisleri,.

Aytaç, Ö (2002). Boş zaman üzerine kuramsal yaklaşımlar, Fırat Üniversitesi Sosyal Bilimler Dergisi, $12(1), 232-233$.

Aslan,Y \& Eratay,E., (2009). Zihin engelli bireylere kumaş üzerine çizilen desene pul işleme becerisinin öğretiminde eşzamanlı ipucuyla öğretimin etkililiği Ankara Üniversitesi Ĕ̆itim Bilimleri Fakültesi Özel Eğitim Dergisi, 2009, 10(2) 15-34.

Aykut, Ç., Dayı, E., Emecen-Dağseven, D.\& Karasu, N. (2014). Zihin engelli öğrencilere küçük grup öğretimi sırasında video ipucu kullanılarak zincirleme becerilerin kazandırılması. Kuram ve Uygulamada Ĕgitim Bilimleri. 14(3), 1075-1087.

Blum-Dimaya, A., Reeve, S.A., Reeve, K.F., \& Hoch, H. (2010). Teaching children with autism to play a video game using activity schedules and game-embedded simultaneous video modeling. Education and Treatment of Children, 33(3), 351-370.

Bolat, Y. ve Tekin, M. (2017). Üstün yeteneklilerin eğitimi araştırmalarında eğilimler: Yöntem bilimsel bir analiz, International Journal Of Eurasia Social Sciences, Vol: 8, Issue: 27, pp. (609-629).

Chan, J. M., Lambdin, L., Van Laarhoven, T. \& Johnson, J. W. (2013). Teaching leisure skills to an adult with developmental disabilities using a video prompting intervention package. Education and Training in Autism and Developmental Disabilities, 48(3), 412-420.

Carlile, K. A., Reeve, S. A., Reeve, K. F., \& DeBar, R. M. (2013). Using activity schedules on the iPod touch to teach leisure skills to children with autism. Education and Treatment of Children, 36(2), 33-57. Retrieved from http://muse.jhu.edu/journals/education_and_treatment_of_children/v036/ 36.2.carlile.html

Coşkun, İ., Dündar, Ş., \& Parlak, C. (2014). Türkiye'de özel eğitim alanında yapılmış lisansüstü tezlerin çeşitli değiş̧kenler açısından incelenmesi(2008-2013). Ege Eğitim Dergisi, 15(2), 375-396.

Chan, J. M., Lambdin, L., Graham, K., Fragale, C. \& Davis T. (2014). A Picture-based activity schedule intervention to teach adults with mild intellectual disability to use an iPad during a leisure activity. Journal of Behavioral Education, 23, 247- 257.

Cannella-Malone, H. I., Miller, O., Schaefer, J. M., Jimenez, E. D., Justin, E., \& Sabielny, L. M. (2016). Using video prompting to teach leisure skills to students with significant disabilities. Exceptional Children, 82(4): 463-478

Çelik, P., Sarı, M. M. \& Yıldırım-Doğru, S. (2015). Türkiye'de ve Avrupa'da 2000-2013 yılları arasında özel gereksinimli çocuklarla ilgili yapılmış olan müzik eğitimi çalışmalarının değerlendirilmesi. Uluslararası Eğitim Bilimleri Dergisi, 2(1), 10-28.

Çuhadar, S. (2008). Resimli etkinlik çizelgeleri ile sunulan öğretim sürecinin otistik özellikler gösteren çocukların serbest zaman becerilerini ögrrenmeleri üzerindeki etkililiği. Yayınlanmamış Doktora Tezi, Anadolu Üniversitesi, Eğitim Bilimleri Enstitüsü, Eskişehir.

Çankaya, Ö. (2011). Zihinsel engelli ögrencilere haroşa örgü örme becerisinin ögretiminde eş zamanlı ipucuyla öğretimin etkililiği. Yüksek Lisans Tezi, Abant İzzet Baysal Üniversitesi Sosyal Bilimler Enstitüsü, Bolu.

Çay, E., \& Özbey, F. (2016). Zihinsel yetersizliği olan öğrencilere gitarla ritim atma becerisinin öğretiminde eşzamanlı ipucuyla öğretimin etkililiği. VII. Hisarlı Ahmet Sempozyumunda sunulmuş bildiri, Kütahya, Türkiye.

Eldeniz Çetin, M., \& Çay, E. (2016). Zihinsel yetersizliği olan öğrencilere bowling becerisinin öğretiminde eşzamanlı ipucunun etkililiği. Sosyal Bilimler Dergisi, 3(9), 441-455.

Güven, D., \& Vuran, S. (2015). Otizm spektrum bozukluğu olan bireylerin sosyal becerilerini geliştirilmesinde grup müdahaleleri. Ankara Üniversitesi Eğitim Bilimleri Fakültesi Özel Ĕgitim Dergisi, 16(1), 29-51.

Greenhalgh, T. (1997). How to read a paper: Papers that summarize other papers (systematic reviews and meta-analyses). $B M J, 315,672-675$. 
Gay, L. R., Mills, G. E., \& Airasian, P. (2006). Educational research: Competencies for analysis and application. New Jersey: Merill Prentice Hall

Gökmen, C., Tekinarslan, E. \& Tekinarslan, İ., Ç., (2015). Zihinsel yetersizliği olan öğrencilere bilgisayarda eğitsel cd izleme becerisinin öğretiminde eşzamanlı ipucuyla öğretimin etkililiği Abant İzzet Baysal Üniversitesi Eğitim Fakültesi Dergisi, 15(Özel Sayl), 190-217.

Hacioğlu, N., Gökdeniz, A. \& Dinç, Y. (2009), Boş zaman ve rekreasyon yönetimi, Ankara: Detay Yayıncilik.

Hammond, D.L., Whatley, A.D., Ayres, K.M. \& Gast, D.L. (2010). Effectiveness of video modeling to teach "ipod" use to students with moderate intellectual disabilities. Education and Training in Autism and Developmental Disabilities, 45(4), 525-538.

Kılıçkaya, A. \& Zelyurt, H. (2015). Okul öncesi programlarında özel gereksinimli bireylerin yer alma durumlarının incelenmesi (1989-2013). Uluslararası Türk Ë̆itim Bilimleri Dergisi, 200-212.

Kizir, M., \& Çifci-Tekinarslan, İ. (2016). İşitme yetersizliği olan bireylere sosyal beceri öğretimi: Bir gözden geçirme. Current Research in Education, 2(3), 149-164.

Kagohara, D. M. (2011). Three student with developmental disabilities learn to operate an iPod toAccess age-appropriate entertaintment videos. Journal of Behavioral Education, 20, 33-43.

Kagohara, D., Sigafoos, J., Achmadi, D., van der Meer, L., O’Reilly, M. F. \& Lancioni, G. E. (2011). Teaching students with developmental disabilities to operate an iPod Touch to listen to music. Research in Developmental Disabilities, 32, 2987-2992.

Kurt, O. (2006) Otistik özellikler gösteren çocuklara zincirleme serbest zaman becerilerinin öğretiminde sabit bekleme süreli ögrretimin ve eşzamanl ipucuyla öğretimin gömülü öğretimle sunulmasının etkililik ve verimlilikleri. Anadolu Üniversitesi Eğitim Bilimleri Enstitüsü, Eskişehir.

Lustyk KB, Widman L, Paschane AA, \& Olson, KC (2004). Physical activity and quality of life: Assessing the influence of activity frequency, intensity, volume, and motives. Behavioral Medicine, 30, 124-131.

Mull RF, Bayless KG, Ross CM, \& Jamieson LM. (1997). Recreational sport management. (3th Edition) USA: Human Kinetics.

MEGEP, Serbest zaman etkinlikleri (2008). Ankara: Milli Eğitim Bakanlığı.

Mosston, M., \& Ashworth, S., (2000). Çeviri : Eda Tüzemen. Düzenleme; Giyasettin Demirhan, Beden eğitimi öğretimi, Ankara: Bağırgan Yayınevi.

Olçay-Gül, S., \& Vuran, S. (2010). Sosyal becerilerin öğretiminde video model yöntemiyle yürütülen araştırmaların analizi. Kuram ve Uygulamada Ĕ̈itim Bilimleri, 10(1), 217-274.

Önder S. (2003). Selçuk Üniversitesi öğrencilerinin rekreasyonel eğilim ve taleplerinin belirlenmesi üzerine bir araştırma. Selçuk Üniversitesi. Ziraat Fakültesi Dergisi, 17 (32), 31-38.

Özbey, F. \& Diken, I. H. (2010). Review of studies on job-vocational education and employment of individuals with mental disability. Special Education Journal, 11(2), 19-42.

Seward, J., Schuster, J. W., Ault, M. J., Collins, B. C., \& Hall, M. (2014). Comparing simultaneous prompting and constant time delay to teach leisure skills to students with moderate intellectual disability. Education and Training in Autism and Developmental Disabilities, 49(3), 381-395.

Schleien, S., Meyer, L., Heyne, L.\& Biel Brandt, B. (1995). Lifelong leisure skills and lifestyles for persons with developmental disabilities. Baltimore: Paul H. Brookes.

Stumbo, N. (1992). Leisure education II: More activities and resources. State College, PA: Venture.

Sucuoğlu, B. (2009). Zihin engelliler ve eğitimleri. Ankara: Kök Yayıncılık.

Trainor, S., Delfabbro, P., Anderson, S. \& Winefield, A. ( 2009). Leisure activities and adolescent psychological well being. Journal of Adolescence,3(03), 8-13.

Torkildsen G. (2005). Recreation and leisure management (5th Edition). London and New York: Routledge, Taylor and Francis Group. 
Toper-Korkmaz, Ö. (2012). Basmakalıp (Stereotipik) davranışların azaltılmasında yeni bir strateji: Tepkiyi yarıda kesme ve yönlendirme. Özel Eğitim Dergisi, 13(1).

Vuran, S. \& Sönmez, M. (2008). Sosyal geçerlik kavramı ve Türkiye'de özel eğitim alanında yürütülen lisansüstü tezlerde sosyal geçerliğin değerlendirilmesi. Ankara Üniversitesi Ĕ̆itim Bilimleri Fakültesi, 9(1), 55-65.

Yücesoy-Özkan, Ş. \& Sönmez, M. (2011). Yetersizliği olan bireylerle yapılmış ve kendini yönetme stratejilerinin kullanıldığı tek denekli araştırmaların incelenmesi: Bir meta-analiz çalışması. Kuram ve Uygulamada Eğitim Bilimleri, 11, 795-821.

Yılmaz, A., Şentürk, U., \& Demir E., (2015). Zihinsel engellilerde fiziksel aktiviteye yönelik uygulamaların içerik analizi. Akademik Sosyal Araştırmalar Dergisi, 13, 312-327.

Yücesoy-Özkan, Ş. \& Gürsel, O., (2006). Zihinsel yetersizliği olan öğrencilere fotokopi çekme becerisinin öğretiminde eşzamanlı ipucuyla öğretimin etkililiği. Ankara Üniversitesi Ĕgitim Bilimleri Fakültesi Özel Ĕgitim Dergisi, 7(2), 29-45.

Yilmaz, I., Birkan, B., Konukman, E, \& Erkan, M. (2005). Using constant time delay procedure to teach aquatic play skills for children with autism. Education and Training in Autism ve Developmental Disabilities, 40(1), 171-182.

Yanardağ, M., Birkan, B., Yılmaz, İ., Konukman, F., Agbuga, B., \& Lieberman, L. (2011). The effects of least-to-most prompting procedure in teaching basic tennis skills to children with autism. Kinesiology: International Journal of Fundamental and Applied Kinesiology, 4 (1), 44-55. 


\section{Extended Abstract}

\section{Introduction}

There are various definitions of the term 'leisure time' available in the literature. It is defined as the remaining time period after doing daily duties during which one can entertain and manage himself/herself without any pressure and feel happy. While individuals demonstrating normal development are able to plan how to spend their leisure time, individuals with special needs may need guidance or training in that. In this process, activities and skills designed by taking individual differences into consideration not only provide children with social, emotional and psychological benefits but also help them develop socially accepted behaviors and improve their interaction with others. In addition, a well-planned implementation of such activities and skills in group training is also significant since the aim is the integration of a student with special needs with his/her friends and the focus is on his/her abilities rather than disabilities. This study aimed to examine the studies on leisure time and leisure time skills of individuals with special needs which were conducted in Turkey and abroad between 2005 and 2016 in order to describe them based on different variables.

\section{Method}

In this study, the available research aiming to provide leisure time skills to individuals with special needs was investigated through descriptive analysis. The research included in this study was selected considering some criteria: a) being published in international refereed journals on education and special education between 2005 and 2016, b) being conducted on individuals with special needs, c) being based on single subject research method, d) its focusing on leisure time skills. In order to reach the research available in the databases of Google Academic and Eric that lies within the scope of this study, articles published as full texts were scanned. The keywords used while scanning the literature were as follows- leisure time, leisure time skills, disabilities and leisure time, disabilities and leisure time skills, individuals with special needs and leisure time.

\section{Results and Discussion}

It was observed that all of the studies under examination had looked at subjects with various disabilities which included intellectual disability, developmental disability, severe disability and autism spectrum disorder. According to the results, off all the subjects participated in these 19 studies ( $\mathrm{n}=67), \% 11.94(\mathrm{n}=8)$ were between the ages of 7 and 9, \%5.97 $(\mathrm{n}=4)$ were between the ages of 8 and 12, \%5.97 (n=4) were between the ages of 9 and 12, \%4.47 (n=3) were between the ages of 11 and 13,\%4.47 (n=3) were between the ages of 12 and 14, \%13.43 (n=9) were between the ages of 12 and 21, \%5.97 ( $n=4)$ were between the ages of 14 and 17, \%4.47 (n=3) were at the ages of 15 and 16, \%4.47 (n=3) were between the ages of 15 and 19,\%11.94 $(n=8)$ were between the ages of 15 and 20,\%4.47 $(n=3)$ were between the ages of 16 and 23,\%8.95 $(\mathrm{n}=6)$ were between the ages of 17 and $18, \% 4.47(\mathrm{n}=3)$ were between the ages of 19 and 22, $\% 2.98(\mathrm{n}=2)$ were between the ages of 21 and 23, \%4.47 $(\mathrm{n}=3)$ were between the ages of 33 and 51 , and \%1.49 $(\mathrm{n}=1)$ were at the age of 35. Moreover, the study revealed that simultaneous prompting, constant time delay prompting, video prompting, most-to-least prompting, video modelling, activity table and least-to-most prompting techniques were used to teach target 
behaviors. Also, these studies were carried out in different contexts such as classrooms, schools, individual training rooms, swimming pools, private special education centers, sports halls, painting classrooms, bowling halls and study halls. In 100\% of the studies ( $n=19)$, skills analysis recording technique was employed to collect data. Similarly, in 100\% of the studies (n $=19$ ), data on both application reliability and inter-rater reliability were collected together. Furthermore, data on social validity were collected in $36.84 \%$ of the studies $(n=7)$. Among the studies in which social validity data were collected, $10.52 \%(\mathrm{n}=2)$ aimed at gathering data on mothers' views, whereas in $5.26 \%(\mathrm{n}=1)$, data on both parents views were collected. Within the scope of these 19 studies, various applications which aimed at developing such skills as starting a CD player, photocopying, spangling, knitting brick and mortar, watching educational CDs on computer, orange peeling, stitch knitting, dog origami making, bowling, rhythm throwing on the guitar, playing water games, making a clay basket, playing video games, using an I-pod, acquiring basic tennis skills, painting, listening to music, taking photos, playing card games, playing dart, playing basketball, doing air rocket with paper and flying it, blowing bubbles with gum, playing dominoes, doing puzzles and taking selfies were run.

It was seen that the biggest group of subjects involved in these 19 studies was the mental disability group with $52.63 \%$. It was respectively followed by the autism spectrum disorder group with $26.31 \%$, the developmental disability group with $15.78 \%$, and the severe disability group with $5.26 \%$. Therefore, the least studied disability group was the severe disability one. The findings of the study show that all these studies were conducted in familiar contexts such as schools, classrooms, individual training rooms, painting classrooms, study halls, etc. Skills' functionality and active use in any environment once they are obtained seem to be very important. The fact that social validity data on not only methods used but also target behaviors were collected in these studies is also a reflection of their nature as research. Moreover, it was seen that parents, families, undergraduate students, academicians, personnel, subjects themselves and teachers were asked for their opinions on the target behaviors and the methods during data collection. The analyses of the research that lies within the scope of this study were performed based on the data on subject characteristics, environment, method, target behavior, data collection techniques, model, reliability and social validity. It was observed that a limited number of studies were conducted on the acquisition of leisure time skills by individuals with special needs between 2005 and 2016. More research is needed to ensure that these individuals spend their free time in a sterling and efficient manner, and socialize with their peers demonstrating normal development. 